TITLE:

\title{
Geotaxis and leaf-surface preferences mitigate negative effects of a predatory mite on an herbivorous mite.
}

\section{$\operatorname{AUTHOR(S):~}$}

Sudo, Masaaki; Osakabe, Masahiro

\section{CITATION:}

Sudo, Masaaki ... [et al]. Geotaxis and leaf-surface preferences mitigate negative effects of a predatory mite on an herbivorous mite.. Experimental \& applied acarology 2013, 59(4): 409-420

\section{ISSUE DATE:}

2013-04

URL:

http://hdl.handle.net/2433/173404

\section{RIGHT:}

The final publication is available at link.springer.com; この論文は出版 社版でありません。引用の際には出版社版をご確認ご利用ください。; This is not the published version. Please cite only the published version. 


\title{
Geotaxis and leaf-surface preferences mitigate negative effects of a predatory mite
}

\section{on an herbivorous mite}

\section{Masaaki Sudo* and Masahiro Osakabe}

Graduate School of Agriculture, Kyoto University; Oiwake-cho, Kitashirakawa, Sakyo-ku, Kyoto 606-8502, Japan

* Correspondence: E-mail: masaaki@sudori.info

Official website: http://www.sudori.info/

\begin{abstract}
Reproductive success and population growth of an herbivorous mite are limited by activities of phytoseiid predators. However, occurrences on upper vs. lower leaf surfaces are sometimes mismatched between these prey and predators. The mismatch potentially mitigates predation risk for the prey species. We assessed factors that affect mite distributions on leaf surfaces, testing whether the presence of the phytoseiid mite Phytoseius nipponicus alters the leaf-surface distribution and reproductive success of the herbivorous false spider mite Brevipalpus obovatus. The host plant was Viburnum erosum var. punctatum (Adoxaceae). Leaves were set in natural (TRUE) and reversed (upside down; INVERTED) orientations using experimental devices. Both surfaces were accessible to mites. We detected lower and abaxial leaf-surface preferences in $P$. nipponicus. In contrast, upper and adaxial surfaces were preferred by B. obovatus. Thus, prey and predatory mites accumulated on different sides of leaves. Presence of the predator also indirectly decreased egg production in B. obovatus. Brevipalpus obovatus females actively avoided leaf surfaces with elevated predator numbers; these females shifted their distributions and changed oviposition sites to leaf surfaces with fewer predators. In consequence, B. obovatus eggs on the upper sides of leaves were less frequently preyed upon than were those on lower sides. We suggest that upper leaf-surface exploitation in this particular herbivorous mite species mitigates predation risk from phytoseiid mites, which prefer lower leaf surfaces.
\end{abstract}

\section{INTRODUCTION}

The reproductive success and population growth of herbivorous mites may be limited by the activities of phytoseiid predators. However, occurrences on upper and lower leaf surfaces are sometimes mismatched between prey and predators. Such a difference in spatial distribution is likely to mitigate predation risk on the prey species.

Many plant-dwelling mites occur on lower abaxial leaf surfaces (Sudo and Osakabe 2011). However, substantial numbers of Brevipalpus obovatus Donnadieu [a false spider mite (Tenuipalpidae)] individuals occur on upper adaxial leaf surfaces of Viburnum erosum Thunb. var. punctatum Franch. et Sav. (VEP; Adoxaceae), which is a major component of forest vegetation in western Japan (Sudo and Osakabe 2011). Phytoseiid and many other forms of mites occur preferentially on the lower sides of leaves. Field observations confirm that nearly $98 \%$ of motile phytoseiids (mainly Phytoseius spp.) are distributed on lower leaf surfaces (Sudo and Osakabe 2011). Hence, exploitation of VEP upper leaf surfaces by $B$. obovatus may decrease predation pressure from phytoseiid mites.

Hairs and/or trichomes that obstruct prey searching and predation (Krips et al. 1999; Loughner et al. 2010) are generally denser and better developed on abaxial than on adaxial leaf surfaces (Chien and Sussex 1996). Accordingly, predation efficiency may be greater on the adaxial sides of leaves. Indeed, more $B$. obovatus eggs were consumed by Phytoseius nipponicus Ehara (Acari, Phytoseiidae) on adaxial than on abaxial surfaces in laboratory experiments using leaf disks as test substrata (Sudo and Osakabe unpublished data). Under these circumstances, preference for adaxial leaf surfaces would be detrimental for B. obovatus in the face of predation risk from $P$. nipponicus. However, predation is not the only factor affecting risk for prey mite species that can choose between leaf surfaces. Abiotic threats such as 
rainfall, high temperature, desiccation, and solar ultraviolet radiation are more severe on upper leaf surfaces and may also limit distributions of many plant-dwelling mites to lower leaf surfaces. Among these factors, solar ultraviolet radiation has recently been demonstrated to have serious impacts on mite survival and spatial distribution (Weintraub et al. 2007; Ohtsuka and Osakabe 2009; Suzuki et al. 2009; Sakai and Osakabe 2010; Onzo et al. 2010).

Loughner et al. (2010) showed that the predatory mite Typhlodromus pyri Scheuten (Acari: Phytoseiidae) balances a behavioral preference for complex habitat, such as a plant surface with dense trichomes, against a positive geotaxis to increase egg survival. Phytoseiid mites in the genus Phytoseius, which occur abundantly on VEP leaves, are generalist predators that depend on a range of alternative food sources (McMurtry and Croft 1997). Because the prey-predator relationship between $B$. obovatus and $P$. nipponicus is not specific, it may not have a role in leafsurface choices in prey populations. However, if upper leafsurface exploitation mitigates predation risk, B. obovatus should respond behaviorally to the presence of $P$. nipponicus.

In this study, we determined factors that affect leafsurface distribution and tested whether the presence of $P$. nipponicus alters the leaf-surface distribution and reproductive success of $B$. obovatus. We used VEP leaves as substrata and deployed devices that made both surfaces accessible to the mites. VEP leaves were set in natural and inverted (upside down) positions to explore the effects of gravity and heterogeneous microstructure (density of leaf hairs) of leaf surfaces on intra-leaf distributions of the preypredator system.

\section{Materials AND METHODS}

\section{Mites}

We collected B. obovatus occurring on VEP leaves in a secondary broadleaf forest site at Iwakura on the outskirts of Kyoto City (Japan, 3505'28"N, 135046'42"E, 150-160 $\mathrm{m}$ a.s.1.) in September 2009. The mites were reared on VEP leaf disks (abaxial surfaces) placed on water-soaked cotton in Petri dishes in a laboratory at $25^{\circ} \mathrm{C}$ and a $16-\mathrm{h}$ light (L):8-h dark (D) cycle. We used B. obovatus females that were 40-50 days old (measured as the duration of time since the mothers had oviposited the eggs from which they hatched).

Phytoseius nipponicus, a generalist phytoseiid species that is predominant in the foliar mite community on VEP in Kyoto (Sudo et al. 2010), was collected from VEP leaves in Iwakura and reared on VEP leaf disks for 2 days prior to experiments. Phytoseius nipponicus adults (both females and males) were identified by pairs of thick dorsal setae on the coarse plate (Ehara and Gotoh 2009).

\section{Host-plant leaves}

VEP leaves have stellate hairs on both adaxial and abaxial surfaces. Stellate hairs and thick straight hairs grow on veins on abaxial leaf surfaces. Hairs growing from closely neighboring veins hang over the vein axil and form so-called hair-tuft domatia (O’Dowd and Willson 1989).

We collected VEP leaves from four shrubs in Iwakura 2 days before each experiment. Simultaneously, we collected phytoseiid mites described above. Leaves were inserted in plastic bags, brought to the laboratory, and assembled into experimental configurations within 6 hours of collection. Predaceous mites (Phytoseiidae and Stigmaeidae), insects (aphids, gall midges, and thrips), and debris ( $>1$ $\mathrm{mm}$ ) were removed from the leaves with forceps prior to the experiments. Fungivorous mites, herbivorous mites (Eriophyoidea), pollen, and fungi were left on leaf surfaces.

\section{Experimental setups}

To explore the ways in which mites use upper/lower or adaxial/abaxial surfaces, VEP leaves were held in a plastic frame (leaf holder: LH; $29.4 \times 8.4 \times 3.0 \mathrm{~cm}$; Fig. 1) that permitted changes in leaf orientation. Two VEP leaves were held in a $\mathrm{LH}$, and the basal halves of both leaf blades were wrapped in cotton fabric $(15 \times 7 \mathrm{~cm})$. The cotton fabric was fastened onto the frame with adhesive tape (Mask Light Tape \#730, Sekisui Chemical, Osaka). Of the two leaves held on a single LH, one was set with the adaxial surface upward (TRUE gravity) and the other with the abaxial surface upward (INVERTED gravity). To prevent leaves from flooding with water, we painted acrylic emulsion adhesive (\#10824, Konishi, Osaka) where the leaf blade met the cotton fabric (Fig. 1). To prevent mites escaping, we coated leaf surfaces $4 \mathrm{~mm}$ distant from the cotton fabric with sticky grease (Tangle B grease; Fuji Yakuhin Kogyo, 
Tokyo). Available leaf spaces (distal part of the leaf blade measured from the boundary of the sticky grease) were $10.52 \pm 6.12 \mathrm{~cm}^{2}$ (mean \pm SD per leaf surface), $9.60 \pm$ $2.89 \mathrm{~cm}^{2}, 8.62 \pm 1.82 \mathrm{~cm}^{2}$, and $9.34 \pm 2.32 \mathrm{~cm}^{2}$ in the TRUE-gravity configuration without predators, TRUEgravity configuration with predators, INVERTED-gravity configuration without predators, and INVERTED-gravity configuration with predator treatments, respectively. Areas were measured with the Histogram Function of Photoshop Elements ver. 2 software (Adobe Systems, San Jose, CA, USA).

Two LHs (bearing four leaves in total) were placed in rectangular plastic tray $(33.5 \times 25 \times 5 \mathrm{~cm})$ containing distilled water $1 \mathrm{~cm}$ deep. Leaves held in the LHs were supplied with water via the cotton fabric. We maintained LHs on a laboratory shelf at $25^{\circ} \mathrm{C}$ under a L16:D8-h photoperiod. LHs were illuminated with $40 \mathrm{~W}$ fluorescent lamps fixed at $40-\mathrm{cm}$ intervals on a side wall $30 \mathrm{~cm}$ distant from the shelf. We used a crossed design with predators (absent/present) and gravity (TRUE/INVERTED) as independent variables. Two LHs in a single vat were used as duplicates, and leaves collected from the same branch were used as replicates.

\section{Experimental design}

We used a two-way factorial design in August, October,
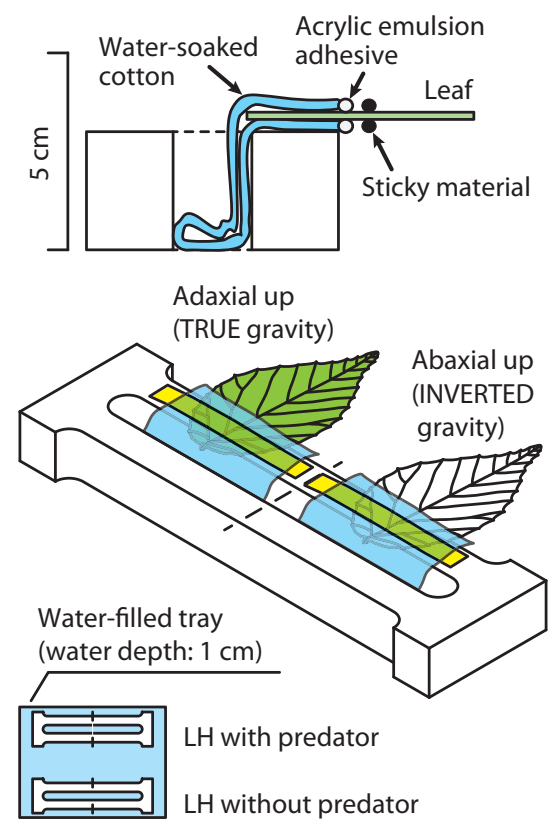

Fig. 1 Leaf holder (LH) used to test the intra-leaf distribution of mites. and November 2010. In each experimental period, we prepared four trays containing two LHs (eight LHs in total). Each tray contained a series of VEP leaves assigned to (1) predator-absent TRUE-gravity, (2) predator-absent INVERTED-gravity, (3) predator-present TRUE-gravity, (4) predator-present INVERTED-gravity treatments.

The day before the beginning of experiment (day zero), we introduced three adult $P$. nipponicus onto two leaves held in one LH (predator-present TRUE/INVERTEDgravity) assembly but not onto the other LH (predatorabsent TRUE/INVERTED-gravity) on the same tray. The following day (day one), three adult B. obovatus females were introduced onto all VEP leaves in the four trays. At daily intervals over the next 10 days (days 2-11), we recorded leaf-surface distributions of mite adults ( $P$. nipponicus and B. obovatus) on each VEP leaf. We first counted the mite adults on the upper sides (whether adaxial or abaxial) of the leaves on each LH using a stereomicroscope with $13 \times$ magnification; we then turned over the LH and immediately counted mites on the lower sides of leaves. Introduced $B$. obovatus females were removed from the leaves on day 11 . If $B$. obovatus females had escaped from the leaves before day 10 , we compensated by adding fresh female conspecifics of the same age. If the number of $P$. nipponicus mites had decreased, we added fresh individuals every day until the egg-hatching rate of $B$. obovatus had been determined. Eggs of $P$. nipponicus were removed from the leaves immediately after we found them.

We recorded the locations of newly-laid $B$. obovatus eggs on the leaves every 24 hours. Subsequently, all eggs were inspected daily until the fate of each egg had been identified as (i) hatched, (ii) lost to predation, or (iii) lost to other causes. Egg vitality was assessed by checking whether each egg was empty and by determining eggshell status. We noted in preliminary observations that hatching larvae clipped their eggshells and left rounded breaks. In contrast, $P$. nipponicus did not leave conspicuous breaks on the eggshells of $B$. obovatus when sucking out egg contents. Hence, when there was a round break on the eggshell and contents had disappeared, we recognized the specimen as a hatched egg. When hatching of a larva was interrupted for more than 24 hours for any reason, the egg was categorized as dead. When all or some contents had disappeared without eggshell clipping, we classified the egg as preyed upon.

In the experiments set up in August 2010, we continued 
observation of $B$. obovatus eggs until day 41 , which is beyond the maximum incubation period of $B$. obovatus eggs at $25^{\circ} \mathrm{C}$ (22 days), which we had determined in our preliminary observations. In October and November, we discontinued observations if no eggs had hatched during the previous 7 days across all treatments; we made this decision because no eggs had hatched after a 7-day no-hatching interval during the August experiments. Eggs that had not hatched by the end of the observation were categorized as dead.

Six leaves withered before the experiments were completed. Thus, we used data collected from 10 leaves in the predator-absent TRUE-gravity and predator-present INVERTED-gravity treatments; data were collected from 11 leaves in the predator-present TRUE-gravity and predator-absent INVERTED-gravity treatments.

\section{Data analyses}

Brevipalpus obovatus eggs that were flooded before hatching or predation (48 of 944 eggs in total) were excluded from egg-fate categorization and included only in the analyses of fecundity. Eggs for which the cause of death was neither predation nor flooding were included in analyses of hatching rate but excluded from comparisons of predation rates between leaf surfaces.

We constructed generalized linear models (GLMs) and generalized linear mixed models (GLMMs) with modules "glm" and "glmmML" (in package glmmML by Broström and Holmberg 2011) of $\mathrm{R}$ software (version 2.10.1; R Development Core Team 2009), respectively. We calculated 95\% confidence intervals (95\% CI) for rates based on the binomial distribution.
Effects of gravity direction and leaf surface on intra-leaf distribution of the predator and $\mathrm{B}$. obovatus adults

GLMMs assuming the binomial distribution (logitlink) were used to evaluate (i) the effects of gravity direction (TRUE/INVERTED) on intra-leaf distribution (lower/ upper side of leaves) of $P$. nipponicus adults and (ii) the effects of gravity direction and predator (absence/presence of $P$. nipponicus) on the intra-leaf distribution of $B$. obovatus adults. Because the counting was repeated 10 times (separate days) on every leaf, leaves were assigned random-effect status in mixed modeling to prevent pseudo-replication. We formulated all combinations among explanatory variables and their two-way interactions into the models, and then selected the appropriate versions based on Akaike's information criterion (AIC).

Avoidance of predator-abundant leaf surfaces by B. obovatus females

The predator-present INVERTED-gravity treatments explored the effects of predator frequency on upper/lower distribution of $B$. obovatus females; this test evaluated whether $B$. obovatus females avoided leaf surfaces with abundant predators. The cumulative number of predators (explanatory variable) and B. obovatus females (response variable) on upper and lower leaf sides were used in a GLM analysis assuming binomial distribution (logit-link) following a Wald test.

Indirect effects of predators on fecundity of $\mathrm{B}$. obovatus

To explore the effects of predator and gravity direction on the fecundity of $B$. obovatus, we used the total number of eggs laid on a single leaf during the first 10 days of the experiment (days 2-11) as the subject variable for GLM

Fig. 2 Distribution of mite adults on VEP leaves, showing proportions of individuals on upper and lower sides of leaves (total frequency through the first 10 days of the experiment). Open and shaded bars indicate proportions of mites on adaxial and abaxial leaf surfaces, respectively. Each circle in the bars signifies the distribution of mites on each leaf, and the segments between circles in "Mother (predator+)" and "Predator" indicate that data came from same leaf.

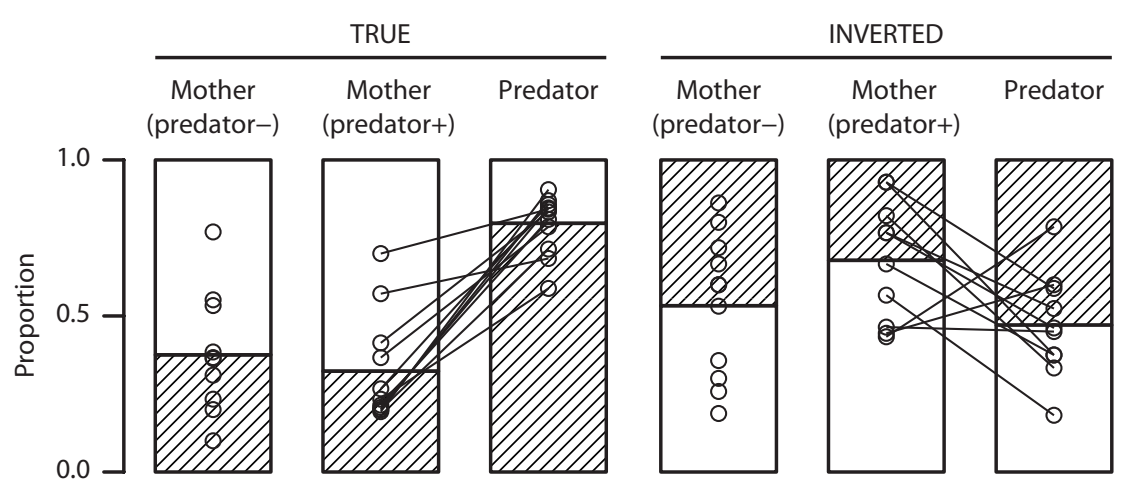


analysis, assuming a Poisson distribution (log-link); we selected suitable models by their AICs.

Factors affecting oviposition-site choice by B. obovatus

To determine factors affecting oviposition-site (leaf surface) choice by $B$. obovatus, we formulated all combinations among surface (leaf surface: adaxial/abaxial), side (direction of leaf surface facing: lower/upper), predator, and their interactions into the GLMMs (log-link, Poisson error) and then selected those with the lowest AIC values. We used total fecundity over 10 days on each leaf surface as the subject variable and offset this by the cumulative observed frequencies of $B$. obovatus mothers on the surface over 10 days. The data obtained from the two surfaces of an identical leaf were clustered for mixed modeling.

Effects of leaf surfaces and direction of gravity on $\mathrm{B}$. obovatus egg hatchability

We used GLMMs (logit-link, binomial error) and model selection by AIC value to explore effects of gravity direction and side on egg predation (preyed upon or not based on individual $B$. obovatus eggs) in the predator-present treatments. Eggs laid on the same leaf were clustered for mixed modeling.

\section{Results}

\section{Effects of direction of gravity and leaf surface on intra- leaf distribution of P. nipponicus and B. obovatus adults}

Median frequencies of $P$. nipponicus adults on upper sides (leaf surface facing upward) of VEP leaves were 16.7 and $54.4 \%$ in TRUE (adaxial leaf surfaces) and INVERTED (abaxial leaf surfaces) gravity treatments, respectively (Fig. 2). The model selection supported a version containing gravity direction as an explanatory variable for the intra-leaf distribution of P. nipponicus adults (Table 1). The coefficient of intercept was negative, whereas the coefficient of gravity direction was positive, but it did not override the effect of the intercept, suggesting that $P$. nipponicus adults prefer the lower sides to the upper sides of VEP leaves (i.e., these mites have positive geotaxis) and tend to favor abaxial over adaxial leaf surfaces.

In predator-absent treatments, medians of $B$. obovatus adult frequencies on the upper sides of VEP leaves were 63.5 and $40.0 \%$ in the TRUE- and INVERTED-gravity

Table 1 GLMM (logit-link, binomial error) for leaf-surface distribution (upper versus lower surface) of $P$. nipponicus adults. AIC $=271.0$ (the selected model) or 287.5 (model with intercept only)

\begin{tabular}{lllll}
\hline & Coefficient & SE & z value & $\operatorname{Pr}(>|z|)$ \\
\hline (Intercept) & -1.535 & 0.196 & -7.828 & $5.00 \times 10^{-15}$ \\
Gravity direction (INVERSE) & 1.358 & 0.258 & 5.269 & $1.37 \times 10^{-7}$ \\
\hline
\end{tabular}

Table 2 GLMM (logit-link, binomial error) for leaf-surface distribution (upper versus lower surface) of B. obovatus adults. AIC $=557.6$ (the selected model) or 558.7 (second lowest AIC value: model lacking the interaction term)

\begin{tabular}{lcccc}
\hline & & & \\
& Coefficient & SE & z value & $\operatorname{Pr}(>|z|)$ \\
\hline (Intercept) & 0.546 & 0.294 & 1.859 & 0.063 \\
Gravity direction (INVERSE) & -0.681 & 0.405 & -1.682 & 0.093 \\
Predator (present) & 0.247 & 0.407 & 0.607 & 0.544 \\
Gravity direction (INVERSE): predator (present) & -1.040 & 0.576 & -1.805 & 0.071 \\
\hline
\end{tabular}

Table 3 Binomial GLM (logit-link) for the effect of predator distribution on leaf-surface distribution (upper surface versus lower) of $B$. obovatus adults in predator-present INVERTED-gravity treatments. The explanatory variable of the model is the total observed frequency of $P$. nipponicus on the upper side of each VEP leaf over 10 days.

\begin{tabular}{lllcl}
\hline & & & & \\
& Coefficient & SE & zalue & $\operatorname{Pr}(>|z|)$ \\
\hline (Intercept) & 0.285 & 0.391 & 0.728 & 0.467 \\
Predator frequency on the upper side & -0.129 & 0.047 & -2.740 & $0.006^{* *}$ \\
\hline
\end{tabular}


Table 4 GLMM (log-link, Poisson error) for 10-day fecundity of B. obovatus on each surface of VEP leaves offset by the observed frequencies of the mothers on each surface. AIC $=180.9$ (the selected model) and 181.7 (the second lowest AIC value: model lacking the surface $\times$ predator interaction term)

\begin{tabular}{lllll}
\hline & Coefficient & SE & z value & $\operatorname{Pr}(>|z|)$ \\
\hline (Intercept) & -0.392 & 0.118 & -3.334 & $8.57 \times 10^{-4}$ \\
Side (upward) & 0.123 & 0.071 & 1.738 & 0.082 \\
Surface (adaxial) & 0.102 & 0.098 & 1.048 & 0.295 \\
Predator (present) & 0.009 & 0.158 & 0.059 & 0.953 \\
Surface (adaxial): predator (present) & -0.243 & 0.144 & -1.686 & 0.092 \\
\hline
\end{tabular}

treatments, respectively (Fig. 2). In the predator-present treatments, these medians changed to 76.7 and $28.3 \%$ in the TRUE- and INVERTED-gravity treatments, respectively. Model selection for the intra-leaf distribution of $B$. obovatus adults supported a version containing gravity direction, predator (absence/presence), and their interaction term as explanatory variables (Table 2). The coefficient of the intercept was positive, whereas the coefficient of gravity direction was negative, overriding the effect of the intercept, indicating a preference for adaxial over abaxial surfaces and for the upper over the lower side of VEP leaves (i.e., negative geotaxis) in B. obovatus females. The positive coefficient of predator and the negative coefficient of the interaction term (gravity direction $\times$ predator) suggest that the presence of $P$. nipponicus motivates $B$. obovatus females to move to adaxial leaf surfaces (Table 2).

Avoidance of predator-abundant leaf surfaces by $B$. obovatus

Although $P$. nipponicus adults were concentrated on lower sides of VEP leaves under the TRUE-gravity configuration, the distribution of predators was divided between upper and lower sides (Fig. 2) on inverted leaves. GLM analysis followed by Wald testing demonstrated that $P$. nipponicus frequency had negative effects on the frequency of $B$. obovatus females present on the same leaf side; the coefficient was -0.12942 (Table 3 ). This suggests that $B$. obovatus females actively avoided predator-abundant leaf sides regardless of leaf surface type (adaxial/abaxial).

Indirect effects of predators on the fecundity of $B$. obovatus

The numbers of eggs per leaf laid by three B. obovatus females over 10 days were $24.0 \pm 3.31$ (mean \pm SE), $21.1 \pm$ $2.64,24.6 \pm 2.86$, and $20.1 \pm 3.05$ in the predator-absent TRUE-gravity, the predator-present TRUE-gravity the predator-absent INVERTED-gravity and the predatorpresent INVERTED-gravity treatments, respectively. Model selection supported the GLM containing only predator $(\mathrm{AIC}=360.8)$ as an explanatory variable over a version containing both gravity direction and predator but lacking the interaction term (the second lowest AIC: $\mathrm{AIC}=$ 362.8). This suggests that the fecundity of B. obovatus over both leaf surfaces was reduced by the presence of predators (indirect effects) but was not affected by direction of gravity.

\section{Factors affecting oviposition site choice by $B$. obovatus}

Distribution of B. obovatus eggs was obviously biased toward adaxial leaf surfaces (Fig. 3), and the upper side tended to be preferred over the lower as an oviposition site. The

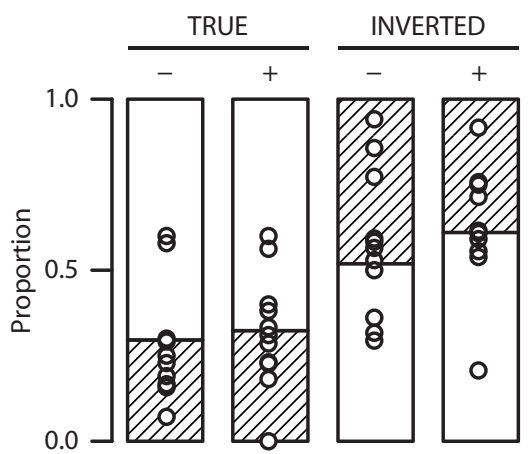

Fig. 3 Distributions of $B$. obovatus eggs on leaves in the predator-absent/present TRUE/INVERTED-gravity treatments. Open bars indicate the proportions of eggs oviposited on adaxial surfaces, and shaded bars indicate proportions on abaxial sides. Minus and plus signs above the bars indicate predator-absent and predator-present treatments, respectively. Circles in the bars represent the proportions of eggs laid on the lower surfaces of each leaf. 
proportion of eggs laid on adaxial surfaces was $0.704(\mathrm{n}=$ 240, 95\% CI: 0.642-0.761) in the predator-absent TRUEgravity treatments, $0.677(\mathrm{n}=232,95 \% \mathrm{CI}: 0.612-0.736)$ in the predator-present TRUE-gravity treatments, 0.518 $(\mathrm{n}=272,95 \% \mathrm{CI}: 0.457-0.579)$ in the predator-absent INVERTED-gravity treatments, and $0.610(\mathrm{n}=200,95 \%$ CI: 0.539-0.678) in the predator-present INVERTEDgravity treatments. Though these distributions of eggs (Fig. 3) resembled the upper-lower frequency ratios of B. obovatus mothers (Fig. 2), environmental factors also affected the egg-production rate in individual females. Poisson GLMMs and subsequent model selection supported the selection of side, surface, predator, and the two-way surface $\times$ predator interaction as explanatory variables for 10-day fecundity on the two leaf surfaces offset by observed frequencies of B. obovatus mothers (Table 4). When P. nipponicus was absent, the coefficients of the models when mothers were on the leaf sides facing upward were 0.123 units higher than coefficients for models when mothers were on surfaces facing downward (signifying a fecundity increase of $13 \%$ in the natural logarithm-linked model). When mothers were on adaxial surfaces, coefficients were 0.102 units higher than when they were on abaxial surfaces (an increase of $11 \%)$. On the adaxial leaf surfaces, the introduction of $P$. nipponicus decreased fecundity by 0.233 units (a decrease of $21 \%)$. In contrast, the presence of predators scarcely affected fecundity ( 0.009 units; $1 \%$ increase) on abaxial surfaces.

Effects of leaf surfaces and direction of gravity on $B$. obovatus egg hatchability

When predators were absent, almost all B. obovatus eggs hatched regardless of leaf surface. In predator-absent TRUE-gravity treatments, the hatchability ratios were $0.975(\mathrm{n}=159,95 \%$ CI: $0.937-0.993)$ and $0.943(\mathrm{n}=70$, 95\% CI: 0.860-0.984) on adaxial (upper) and abaxial (lower) leaf surfaces, respectively. In predator-absent
INVERTED-gravity treatments, hatchabilities were 1.000 $(\mathrm{n}=129,95 \%$ CI: $0.972-1.000)$ and $0.984(\mathrm{n}=124,95 \%$ CI: 0.943-0.998) on abaxial (upper) and adaxial (lower) leaf surfaces, respectively.

However, egg hatchability decreased in the presence of predators, and the magnitude of the reduction was greater on the lower sides of leaves (Fig. 4). In predator-present TRUE-gravity treatments, the hatchabilities were 0.538 (n $=145,95 \%$ CI: $0.453-0.621)$ and $0.440(\mathrm{n}=75,95 \% \mathrm{CI}$ : 0.325-0.559) on upper (adaxial) and lower (abaxial) sides of leaves, respectively. In the predator-present INVERTEDgravity treatments, hatchabilities were $0.744(\mathrm{n}=78,95 \%$ CI: $0.632-0.836)$ and $0.569(\mathrm{n}=116,95 \%$ CI: $0.474-$ 0.661 ) on upper (abaxial) and lower (adaxial) sides of leaves, respectively. The model selection supported the selection of gravity direction (TRUE/INVERTED) and side (upper/ lower) as explanatory variables for egg predation risk (Table 5). This suggests that predation rate was lower on the upper than on the lower sides of VEP leaves; the INVERTEDgravity treatment moderated the risk of predation by $P$. nipponicus for $B$. obovatus eggs.

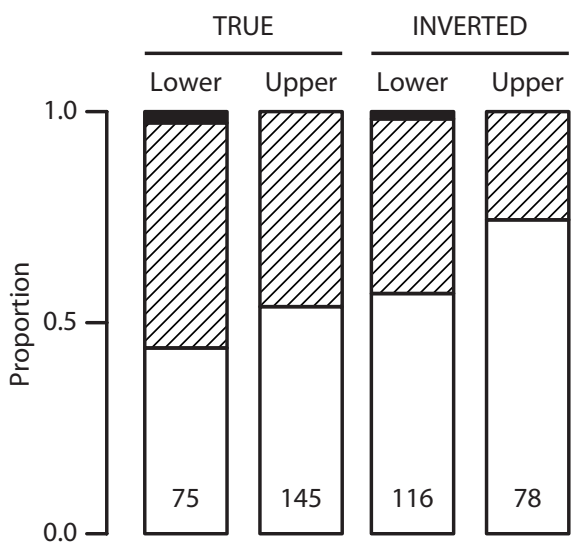

Fig. 4 Proportion of B. obovatus eggs that hatched (open bars), died from predation (shaded bars), and died due to other factors (filled bars) on upper and lower surfaces of VEP leaves in the predator-present TRUE- and INVERTED-gravity treatments. Numbers in the bars are total numbers of eggs observed in each treatment.

Table 5 GLMM (logit-link, binomial error) of predation risk (preyed upon vs. not preyed upon) for each B. obovatus egg on a VEP leaf with the predator. Eggs that died (but were not preyed upon) were excluded from the analysis. AIC = 531.1 (the selected model) and 532.9 (second lowest model, which contains the interaction term)

\begin{tabular}{lllll}
\hline & Coefficient & SE & z value & $\operatorname{Pr}(>|\mathrm{z}|)$ \\
\hline (Intercept) & 0.252 & 0.318 & 0.794 & 0.427 \\
Side (upper) & -0.491 & 0.236 & -2.084 & 0.037 \\
Gravity direction (INVERSE) & -0.664 & 0.413 & -1.608 & 0.108 \\
\hline
\end{tabular}


Most P. nipponicus predation on individual B. obovatus eggs occurred within the first half of the egg period. The mean incubation period for B. obovatus eggs was 11.66 days, and this was unaffected by gravity direction, leaf surface (adaxial or abaxial), and absence/presence of predators (Poisson GLMM analysis with log-link). The 95th percentiles of ages of eggs eaten by the predator were 5.7 and 6 days on predator-present leaves with TRUE- or INVERTED-gravity treatments, respectively.

\section{DisCUSSION}

Abaxial surfaces of VEP leaves have more stellate hairs than do adaxial surfaces. Dense leaf hairs protect eggs of B. obovatus from $P$. nipponicus predation (Sudo and Osakabe unpublished data). Nevertheless, B. obovatus adults occur more frequently and oviposit more often on adaxial leaf surfaces than on the obverse surfaces. On first consideration, this behavior may seem inappropriate in the face of losses to predation, but it may be explained by the effects of gravity and leaf-surface architecture on local predator density. Positive geotaxis and a preference for surface environments on the abaxial surfaces of VEP leaves accounted for the concentration of $P$. nipponicus population on lower abaxial leaf surfaces. Conversely, B. obovatus had negative geotaxis and a preference for the adaxial surface over the abaxial surface. Both the direction of gravity pull and leaf-surface architecture likely explain the occurrences of $P$. nipponicus and B. obovatus on different surfaces of the same leaf, though gravity had less effect on the distribution of $B$. obovatus in comparison with leaf-surface architecture. This spatial segregation would clearly reduce opportunities for encounters between predator and prey. In this study, the mites were confined to a single leaf. However, the prey might move off of the leaf in the presence of the predator. Future studies will show how the prey mites respond to the predator presence under the circumstance that they are accessible to the adjoining leaves.

The daily fecundity of $B$. obovatus on predator-present leaves was approximately 5/6 that on predator-free leaves. We interpret this reduction as an indirect, negative predator effect. Although the extent of fecundity reduction was greater than in previous experiments using VEP leaf discs, $B$. obovatus oviposition rates on adaxial and abaxial leaf surfaces in the presence of predators decreased by $1 / 2$ and $2 / 3$, respectively, in comparison with predator-free surfaces
(Sudo and Osakabe unpublished data; three B. obovatus mothers versus two predators per leaf disc). In addition to having reversed preferences for gravity direction and leaf surfaces in comparison with $P$. nipponicus, B. obovatus adults actively changed their leaf-surface distribution to avoid the predator. This change in distribution indicates that the decrease in $B$. obovatus fecundity was mitigated when both leaf surfaces were available, paralleling circumstances in nature. Thus, the presence of the predator is a significant determinant of intra-leaf distribution of B. obovatus.

The egg-predation rate was lower on the upper sides of VEP leaves than on lower sides. Reduced predation risk may compensate for the reduced frequency of sheltered sites for oviposition on the upper adaxial surface of a VEP leaf. Effects of leaf-surface microstructures (e.g., hairs, glandular trichomes, and domatia) on loss rates of plant mites and their eggs to predation have been investigated previously (van Haren et al. 1987; Krips et al. 1999; Norton et al. 2001; Roda et al. 2001; Kasai et al. 2005), but the effects of leaf side (upper or lower) were scarcely considered in the past. Our findings demonstrate that gravity direction detected by mites on upper and lower leaf surfaces affects prey-predator interactions between B. obovatus and P. nipponicus.

Many mite herbivores lay eggs on upper leaf surfaces only when population densities reach a saturation point on lower-leaf surface (Jeppson 1975). In contrast, the oviposition rate of $B$. obovatus was slightly higher on the upper side than on the lower side of VEP leaves when predators were absent. The hatchability of $B$. obovatus eggs was nearly $90 \%$ on both sides of VEP leaves in the absence of predators. Together with the upper-lower frequency ratio of eggs on wild VEP leaves (35\% of eggs on upper leaf surfaces; Sudo and Osakabe 2011), combined use of upper and lower leaf surfaces of VEP as oviposition sites by $B$. obovatus might represent a strategy by which the species mitigates indirect effects of phytoseiids on both its fecundity and the predation risks on its eggs.

It is possible that $B$. obovatus adults on wild hosts might switch oviposition sites between upper and lower sides of leaves depending on predator presence or density. Although B. obovatus experiences lower levels of regulation by predatory mites on upper sides of leaves than on lower sides, its eggs will be exposed to greater environmental stresses, such as rainfall (Foott 1963) and solar ultraviolet B radiation (Ohtsuka and Osakabe 2009; Onzo et al. 2010), 
on the upper leaf side. The break-even point of declining predation risk and increasing environmental stresses on leaf upper sides will vary with spatio-temporal changes in stressors and the magnitude of environmental tolerance intrinsic to each mite species.

Acknowledgement We thank Prof. H. Amano, Dr. S. Yano and Mr. Y. Sakai, Kyoto University for valuable suggestions. This study was partially supported by Grantin-Aid for JSPS Fellows No. 23.2696 to SM from Japan Society for the Promotion of Science (JSPS).

\section{REFERENCES}

Broström G, Holmberg H (2011) glmmML: Generalized linear models with clustering. version $0.81-8$

Chien JC, Sussex IM (1996) Differential regulation of trichome formation on the adaxial and abaxial leaf surfaces by gibberellins and photoperiod in Arabidopsis thaliana (L.) Heynh. Plant Physiol 111: 1321-1328

Ehara S, Gotoh T (eds) (2009) Colored guide to the plant mites of Japan. Zenkoku Noson Kyoiku Kyokai, Tokyo. 349 pp. (in Japanese)

Foott WH (1963) Competition between two species of mites. II. Factors influencing intensity. Can Entomol 95: 45-57

Haren RJF van, Steenhuis MM, Sabelis MW, Ponti OMB de (1987) Tomato stem trichomes and dispersal success of Phytoseiulus persimilis relative to its prey Tetranychus urticae. Exp Appl Acarol 3: 115-121. doi: 10.1007/BF01270473

Jeppson LR (1975) Chapter 2. Population ecology. In: Jeppson LR, Keifer HH \& Baker EW (eds) Mites injurious to economic plants, pp. 17-46. University of California Press, Berkeley, California

Kasai A, Yano S, Takafuji A (2005) Prey-predator mutualism in a tritrophic system on a camphor tree. Ecol Res 20: 163-166. doi: 10.1007/s11284-004-0030-9

Krips OE, Kleijn PW, Willems PEL, Gols GJZ, Dicke M (1999) Leaf hairs influence searching efficiency and predation rate of the predatory mite Phytoseiuluspersimilis (Acari: Phytoseiidae). Exp Appl Acarol 23: 119-131. doi: 10.1023/A:1006098410165 Loughner R, Wentworth K, Loeb G, Nyrop J (2010) Leaf trichomes influence predatory mite densities through dispersal behavior. Entomol Exp Appl 134: 78-88. doi: 10.1111/j.15707458.2009.00939.x
McMurtry JA, Croft BA (1997) Life styles of phytoseiid mites and their roles as biological control agents. Annu Rev Entomol 42: 291-321 doi: 10.1146/annurev.ento.42.1.291

Norton AP, English-Loeb G, Belden E (2001) Host plant manipulation of natural enemies: leaf domatia protect beneficial mites from insect predators. Oecologia 126: 535542. doi: $10.1007 /$ s004420000556

O'Dowd DJ, Willson MF (1989) Leaf domatia and mites on Australasian plants: ecological and evolutionary implications. Biol J Linn Soc 37: 191-236. doi: 10.1111/j.1095-8312.1989. tb01901.x

Ohtsuka K, Osakabe Mh (2009) Deleterious effects of UV-B radiation on herbivorous spider mites: they can avoid it by remaining on lower leaf surfaces. Environ Entomol 38: 920929. doi: $10.1603 / 022.038 .0346$

Onzo A, Sabelis MW, Hanna R (2010) Effects of ultraviolet radiation on predatory mites and the role of refuges in plant structures. Env Entomol 39: 695-701. doi:10.1603/EN09206

R Development Core Team (2009) R: A language and environment for statistical computing, version 2.10.1. R Foundation for Statistical Computing, Vienna

Roda A, Nyrop J, English-Loeb G, Dicke M (2001) Leaf pubescence and two-spotted spider mite webbing influence phytoseiid behavior and population density. Oecologia 129: 551-560. doi: 10.1007/s004420100762

Sakai Y, Osakabe Mh (2010) Spectrum-specific damage and solar ultraviolet radiation avoidance in the two-spotted spider mite. Photochem Photobiol 86: 925-932.

Sudo M, Osakabe M (2011) Do plant mites commonly prefer the underside of leaves? Exp Appl Acarol 55: 25-38. doi: 10.1007/ s10493-011-9454-4

Sudo M, Nishida S, Itioka T (2010) Seasonal fluctuations in foliar mite populations on Viburnum erosum Thunb. var. punctatum Franch. et Sav. (Adoxaceae) and sympatric shrubs in temperate secondary forests in western Japan. Appl Entomol Zool 45: 405-415. doi: 10.1303/aez.2010.405

Suzuki T, Watanabe M, Takeda M (2009) UV tolerance in the two-spotted spider mite, Tetranychus urticae. J Insect Physiol 55: 649-654.

Weintraub PG, Kleitman S, Alchanatis V, Palevsky E (2007) Factors affecting the distribution of a predatory mite on greenhouse sweet pepper. Exp Appl Acarol 42: 23-35. 